\title{
Predicting E-Procurement Utilization in Independent Commissions in Kenya
}

\author{
Joyce Sang \\ School of Computing and Informatics \\ University of Nairobi, Nairobi, Kenya
}

\author{
Christopher Moturi \\ School of Computing and Informatics \\ University of Nairobi, Nairobi, Kenya
}

\begin{abstract}
E-procurement has recently been introduced in the Kenyan public sector due to the many practical advantages it brings. Usage of the system is still at a very nascent stage. This paper sought to predict e-procurement utilization by analyzing the constructs of the Extended Technology Acceptance Model. The study administered a questionnaire to 229 employees of the 11independent commissions in the country. Regression analysis was done to describe the significance and the strength of relationships between variables. The analysis yielded important findings that partially support research hypotheses. The results indicated that subjective norm and reliability of the system influence utilization of the system while compatibility was insignificant. All the identified elements have correlations with the model elements and in turn impact on the behavioral intention to use the system. This study would influence government technology plans through implementation of policies that enhance adoption of emerging technologies in the public sector.
\end{abstract}

\section{Keywords}

E-procurement, Extended Technology Acceptance Model, Kenya Independent Commissions, Kenya Public Sector

\section{INTRODUCTION}

E-procurement is the process of electronically purchasing goods and services needed for an organization operation (Beauvallet et al. (2011). Over the past decades, public procurement has gained much attention amongst developing countries with procurement budgets in developing countries accounting for about 20 per cent of government expenditure globally (Mlinga, 2009). The advent of the internet, digital connectivity, the explosion and use of e-business models by developed countries are pressuring developing nations to rethink their business model. It is now widely accepted that eprocurement offers increased opportunities for economic development and plays a critical role in promoting economic growth in developing nations. The range of opportunities in eprocurement in developing countries is expanding. Eprocurement is believed to be a powerful enabling tool to address some of the key challenges in public procurement that is inherent in developing countries. E-Procurement offers potentials not just to process enormous quantity of information but also to network, interact, collaborate and communicate across the world (Schoenherr and Tummala, 2007).

In Kenya public procurement has witnessed a number of reforms beginning with the Public Procurement and Disposal Act which led to establishment of the Public Procurement Oversight Authority (PPOA). E-procurement was one of the medium term objectives which were to be implemented as stipulated in the e-government strategy paper (PPOA, 2007) though the implementation of e-procurement has not significantly been visible to date. A number of public procurement entities are still operating the manual procurement process and missing out the e-procurement benefits. Independent commissions in Kenya have also been viewed to be slow in taking up the e-procurement

The general objective of this study was therefore to apply the Extended Technology Acceptance Model (ETAM) in predicting e-procurement adoption in the independent commissions in Kenya. The specific objectives were:

1. To investigate the constructs of ETAM that influence individual intentions to use e-procurement in the independent commissions

2. To examine the role of selected external variables of the model in predicting e-procurement adoption in independent commissions' in Kenya.

3. To propose an ETAM based integrated theoretical framework to support prediction and understanding the intention to use e-procurement system in independent commissions in Kenya.

\section{THEORETICAL MODEL AND HYPOTHESIS}

Technology Acceptance Model (TAM) is one of the wellknown and widely used technology adoption models (Aboelmaged, 2010; Hamner, 2009; Liu,.et al., 2010; Park, 2009; Teo, 2010). TAM has proven to be a theoretical model that has been used to explain and predict user behavior of information technology over the decades (Legris et al 2003). TAM is an influential extension of theory of reasoned action (TRA), according to (Ajzen and Fishbein, 1980). Davis (1989) proposed TAM to explain why a user accepts and uses information technology by adapting TRA.The principal scheme of the original TAM is shown in Figure 1.

The original TAM shows that Perceived Usefulness and Perceived Ease of Use are key constructs in determining users' acceptance and use of technology. As articulated by (Davis et al. 1989) these constructs are defined as follows; Perceived Usefulness is referred to as the degree to which someone believes that using a particular system would enhance their job performance. Perceived Ease of Use is referred to the degree to which someone believes that using a particular system would be free of effort. 


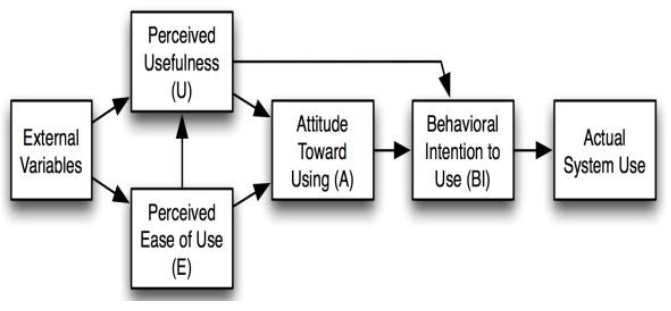

Figure1: Original Technology Acceptance Model

TAM theorizes that perceived usefulness and perceived ease of use are influenced by external variables. Therefore, perceived usefulness and perceived ease of use mediate the effect of external variables on user's attitude and behavioral intention, and therefore actual system use. The author developed an extended technology acceptance model including three external variables. These variables are

- Subjective Norm - The person's perception that most people who are important to him think they should or should not perform the behavior in question.

- Reliability - Reliability refers to a person's perception of a system's reliability and responsiveness during normal operations

- Compatibility - Compatibility is defined as an individual's perception of how relevant the technology is to one's job (Venkatesh et al., 2003).

The components of ETAM are presented in figure 2. The following hypothesis were drawn:

H1. Subjective norm is positively related to perceived usefulness

H2. Subjective norm is positively related to perceived Ease of Use

H3. Reliability is positively related to perceived ease of use

H4. Reliability is positively related to perceived Usefulness

H5. Compatibility is positively related to perceived ease of use

H6. Perceived ease of use is positively related to perceived usefulness

H7. Perceived usefulness is positively related to attitude toward use

H8. Perceived Ease of Use is positively related to attitude toward use

H9. Attitude toward use is positively related to behavioral intention

H10. Behavioral Intentions has positive effect to actual Usage

\section{RESEARCH METHODOLOGY}

\subsection{Data Collection}

The data was gathered exclusively by questionnaire as the research instrument. The questionnaire was designed in line with Extended Technology Acceptance Model. To enhance quality of data obtained, questions were included whereby respondents indicated the extent to which they understood the various variables chosen for the study. Part I was designed to identify demographic attributes of the respondents. It consists of demographic attributes such as age, gender, academic qualification, the position held in the independent commission and the number of years in that position. The questions in Part II were made based on Davis's prior studies with modifications to fit the specific context of the e-procurement in the independent commission but also mainly adapted from the model. This consisted of seven sub-sections, as follows: perceived ease of use (PU), attitude (A), behavioral Individual Usage (B), Compatibility (C), Reliability (R) and Subjective Norm (S) perceived usefulness (PU).

\subsection{Measures}

The measures from the questionnaire were adapted from Extended TAM model and each variable was measured with a weighted scale. All scales were measured using a 5-point Likert scale with the following response options: $1=$ strongly disagree, $2=$ disagree, $3=$ neutral, $4=$ Agree, $5=$ strongly agree. The mean for each variable provides an indication of the average attitude for each variable such that scores closer to 3 indicate a more neutral attitude, values more than 3 indicate a more favorable attitude, and values less than 3 indicate a more unfavorable attitude. Table 2 shows the measurement items that were used to operationalize each construct.

\subsection{Data Analysis}

Data gathered from the survey were analyzed in two stages. In the first stage the questionnaire used in the survey was evaluated. The reliability of the instrument was checked with Chronbach's $\alpha$ measure which was calculated for each questionnaire construct (Table 1). In the second stage of data analysis the dependencies among the model components were studied using the regression analyses.

Table 1: Instruments reliability Cornbach Alpha

\begin{tabular}{|l|c|c|}
\hline Scale & Items & Cronbach \\
\hline Perceived ease of use & 4 & 0.80 \\
\hline Perceived Usefulness & 3 & 0.82 \\
\hline Attitude towards use & 3 & 0.79 \\
\hline Reliability & 3 & 0.76 \\
\hline Behavioral Intention to use & 3 & 0.92 \\
\hline Subjective Norm & 3 & 0.78 \\
\hline Compatibility & 5 & 0.72 \\
\hline
\end{tabular}




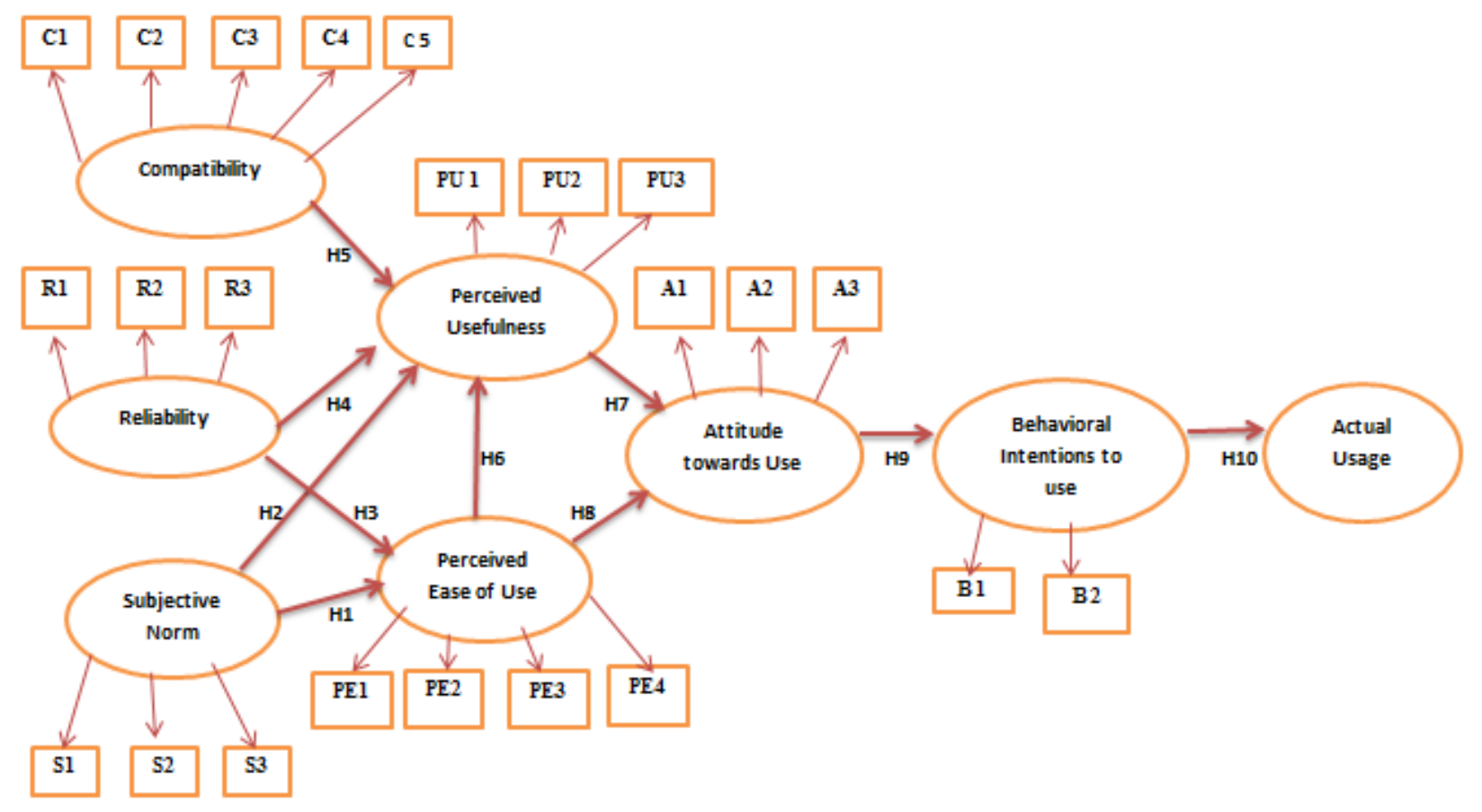

Figure 2: Extended TAM for this study

\section{Table 2: Measurement Items}

Measurement Items
Attitude
A1: Using e-procurement saves time
A2: Using e-procurement is a positive idea
A3: Using e-procurement is good for work
Compatibility
C1: Using e-procurement fits well with anindividual working
style.
C2: Using the system fits the organization style and culture.
C3: Usage of e-procurement system is important.
C4: E-procurement is compatible with all aspects of employees
work.
C5: Using the e-procurement system increases individual
effectiveness
Reliability
R1: It is fast to use e-procurement system
R2: The system is always available for use.
R3: The system application reliably handlesemployee's work.
Perceived ease of use
PE1: Learning to use e-procurement is easy
PE2: Interaction with the system is clear and understandable
PE3: It is easy to become skillful at using e-procurement system
PE4: E-procurement system easy to use.
Perceived usefulness
PU1: E-procurement improves work and life efficiency
informent allows user to easily acquire the
iney need

PU3: Overall, e-procurement is useful

\section{Subjective norm}

S1. Users' bosses think that they should use e-procurement system.

S2. Their colleagues think that they should use e-procurement

S3. The government directive has influenced use of eprocurement.

\section{DATA ANALYSIS AND RESULTS 4.1 Demographics}

The study targeted Independent Commissions of Kenya. Out of all the questionnaires issued, 198 were filled in and returned for analysis, accounting to $86 \%$ of the total target response.

Table 3 lists the demographic characteristics of the sample. The male gender formed majority of the respondents. Respondents between 30 to 50 years formed the largest age group at $(64 \%)$ followed by respondents who were less than 30 years of age $(57 \%)$. The majority of the users who were interviewed were less than 50 years and therefore are quite familiar with information technology.

Table 3: Demographic Information

\begin{tabular}{|c|l|l|}
\hline Variables & Number & Frequency \\
\hline Gender & & \\
\hline Male & 119 & $61 \%$ \\
\hline Female & 79 & $39 \%$ \\
\hline
\end{tabular}




\begin{tabular}{|l|l|l|} 
Age & & \\
\hline Less than 30 years & 57 & $29 \%$ \\
\hline Between 30-50 years & 126 & $64 \%$ \\
\hline More than 50 years & 15 & $8 \%$ \\
\hline Level of Education & & \\
\hline Secondary Education & 10 & $5 \%$ \\
\hline College Diploma & 60 & $30 \%$ \\
\hline Undergraduate Degree & 98 & $49 \%$ \\
\hline Post Graduate Degree & 30 & $15 \%$ \\
\hline Position Held & & \\
\hline Supervisor & 22 & $11 \%$ \\
\hline Officer & 44 & $22 \%$ \\
\hline End User & 132 & $67 \%$ \\
\hline $\begin{array}{l}\text { How long have you been in this } \\
\text { position }\end{array}$ & & \\
\hline Less than 3 years & 97 & $49 \%$ \\
\hline Between 3 to 6 years & 80 & $40 \%$ \\
\hline Above 6 years & 21 & $11 \%$ \\
\hline
\end{tabular}

\begin{tabular}{|l|l|l|l|l|l|} 
H6 & 0.386 & 0.242 & 0.258 & 0.008 & Supported \\
\hline H7 & 0.178 & 0.198 & 0.359 & 0.001 & Supported \\
\hline H8 & 0.18 & 0.19 & 0.267 & 0.003 & Supported \\
\hline H9 & 0.583 & 0.25 & 0.235 & 0.000 & Supported \\
\hline H10 & 0.676 & 0.22 & 0.428 & 0.002 & Supported \\
\hline
\end{tabular}

The intentionof this study was to extend the understanding regarding the adoption of e-procurement using Extended Technology Acceptance model. Survey data from 198 respondents was analyzed and it yielded important findings. The results supported and rejected the search hypotheses. Insightful results were drawn and could be summarized from the research framework.

The first and the second hypothesis represented the relationship between subjective norm and perceived ease of use and perceived usefulness. From the results subjective norm positively and significantly impact e-procurement adoption on both perceived ease of use and perceived usefulness. The first hypothesis comparing coefficients of the study of e-procurement adoption, subjective norm emerges as the most powerful predictor $(\beta=0.992, p<0.000)$ of perceived usefulness. The second hypothesized path which states that subjective norm is positively related to perceived Ease of Use is confirmed with significance relationship with coefficients $(\beta=0.89, p<0.002)$.

A good majority of respondents (79\%) had some good education (diploma and or undergraduate) and therefore could understand the e-procurement system easily. Also, majority of respondents $(67 \%)$ were end users, followed by officers (22\%) and finally the supervisors (11\%). This indicates that majority of the users of the e-procurement system are end users who use it on a day to day basis. In this study 49 percent of respondents have been in the commissions for less than 3 years, another 40 per cent have been in the commission between 3 and 6 years. Only 11\% have been in their positions for more than 6 years. This is explainable due to the reasons that most commissions in Kenya are newly created.

\subsection{Statistical Analysis and Hypotheses Testing}

In line with the study objectives, regression analysis was conducted to examine the relationship between the variables used within this study, and therefore to empirically decide whether to reject or accept an hypothesis. The aimwas to provide a comprehensive regression analysis and theninvestigate the relationship within the variables.

Table 4: Coefficient Table

\begin{tabular}{|l|l|l|l|l|l|}
\hline & \multicolumn{2}{|l|}{$\begin{array}{l}\text { Unstandardized } \\
\text { Coefficients }\end{array}$} & & Sig. & \\
\cline { 2 - 6 } & B & $\begin{array}{l}\text { Std. } \\
\text { Error }\end{array}$ & Beta & & Results \\
\hline H1 & 0.992 & 0.861 & & 0.000 & Supported \\
\hline H2 & 0.89 & 0.292 & 0.123 & 0.002 & Supported \\
\hline H3 & -0.194 & 0.176 & -0.34 & 0.067 & Rejected \\
\hline H4 & 0.776 & 0.252 & 0.128 & 0.000 & Supported \\
\hline H5 & -0.089 & 0.205 & -0.184 & 0.079 & Rejected \\
\hline
\end{tabular}

This singles out the importance of the government directive and how the individuals perceive their bosses to ensure successful implementation of e-procurement services. One possible explanation for this may be justified by the fact that that it is mandatory for the users to use e-procurement. These findings are consistent with the explanation of the TAM model which states that subjective norm have high significance to determine intention to use in a mandatory usage context (Davis et al., 1989).

System reliability reflects people's perception of ease or difficulty in performing the behavior of interest (Ajzen and Fishbein, 1980). System reliability in this study appeared to have insignificant effect on perceived ease of use and significant effect on perceived usefulness. This means, the third hypothesized path $(\mathrm{B}=-0.194, \mathrm{p}=0.067)$ was not confirmed. A plausible explanation to this finding could be the lack of adequate support from the relevant ministry and at the same time the instability of the system which resulted in negative ratings on perceived ease of use.

The fourth hypothesis $(\mathrm{B}=0.476, \mathrm{p}=0.000$ ) shows that there is significant relationship between system reliability and perceived Usefulness. This can be explained that the reliability due to system ability to hand the users work made the users believe that it is useful and free from of physical and mental effort. This relationship though is not quite strong. Public institutions interested in successful utilization of the system may consider increasing the support to the users to increase ratings on reliability of the system. For example; conducting a brief orientation that discusses the functionality of the system before actual implementation.

The hypothesized relationships that compatibility is positively and significantly related to perceived ease of use and in turn influence e-procurement is not confirmed $(\mathrm{B}=-0.089, \mathrm{p}=$ 0.076). System compatibility was measured as a factor was 
not significant construct affecting perceived ease of use. This may be due to the fact that the system was uniformly rolled out to the commissions without considering the fact that different individuals /or commissions have different ways of working. Another possible explanation for this finding could be due to respondents' limited familiarity with software that may reduce their perceived ease of use. This may also be due to insufficient strategic focus and insufficient human resource development to support the system and the users as indicated in the National Treasury of June 2015.

Perceived ease of use emerged in this study as a significant predictor of perceived usefulness $(B=0.386, p=0.008)$. Therefore hypothesis H6 can be confirmed. This is consistent with the constructs of extended technology acceptance model, whereby perceived ease of use predicts perceived usefulness.

The hypothesized path of perceived usefulness positively related to attitude is confirmed as a significant predictor. Since both reported regression results are positive and significantly at 0.178 and 0.001 significant level, Hypothesis seven can be confirmed. This result is consistent with the original TAM proposed by Davis whereby when the users believe that using acertain system would enhance their job performance, it enhances their attitude towards using of that system. The relationship though is not strong enough and therefore the researcher suggests further studies to explain the possible underlying factor.

The hypothesized path of Perceived Ease of Use emerging to have positive and significant relationship to attitude was confirmed in this study. This result was expected because prior research and explanation of TAM clearly demonstrates that perceived ease of use have a significant relationship to attitude. Reviewing the results from the study $(\mathrm{B}=0.18, \mathrm{p}=$ $0.003)$, it clearly shows that this hypothesis is supported.

Hypothesis nine; Attitude toward use is positively related to behavioral intention was confirmed in this study. From the analysis result, it can be observed that there is a significant and positive relationship between the Attitude and behavioral Intention to use the system. Therefore, this hypothesis is supported. This is consistent with the explanation of the original TAM where attitude towards use positively affects intention to use the system.

Finally, the behavioral Intention to use has positive effect to actual Usage. The relationship between behavioral intention and actual individual use $(\mathrm{B}=0.676, \mathrm{p}=0.002)$ is statistically significant with a confidence level of 0.002 . These results provide support for hypothesis ten. From this result it can be concluded that the users in the independent commission are likely to use the system once more support is provided that increases reliability of the system. Moretrainings also need to be provided to the users.

\section{DISCUSSION}

The first objective of this paper was to investigate the constructs of ETAM that influence the adoption and continuous utilization of the e-procurement system by independent commissions in Kenya. Three potential factors (Subjective norm, Compatibility and Reliability) which represent the external variables of the extended TAM were investigated. Since all these variables are found to have correlation on the Perceived Usefulness and Perceived Ease of Use, it can be asserted that they also affect the behavioral intentions to use the system. Therefore, all these variables are relevant to be analyzed for this study.
The second objective was to examine the role of selected external variables. It was confirmed that indeed some variables were considered to be more significant than others. Subjective norm and system reliability were significant while compatibility to the job was insignificant.

The final objective was to propose an ETAM based integrated theoretical framework to support prediction and understanding the intention to use e-procurement system in independent commissions in Kenya. The statistical analysis shows that the findings of the current study are consistent with the original TAM findings. All TAM-related hypotheses within this study were proven to have positive correlations that are statistically significant. The research framework developed partially supported the hypothesis.

\section{CONCLUSION}

From the study, it can be concluded that only two external variables considered in the model influence utilization of eprocurement system. The third variable compatibility does not influence adoption of the system. Therefore, we can assert that subjective norm and reliability variables included in the model represent the potential elements that influence utilization of the system.

This study has proposed a theoretical framework based on a robust extended technology acceptance model. This framework can be used to predict the behavioral intention to use an e-procurement system prior to and after the actual implementation. Moreover, this study contributes to the efforts to empirically validate Extended Technology Acceptance Model in a developing country like Kenya. Most significantly, this study could benefit the government in their future plans to adopt other technologies by implementing policies that enhance adoption of emerging technologies in the public sector.

However, theproposed model has an average explanatory power. This could be especially valuable for researchers to addmore variables beyond TAM when predicting eprocurement adoption. In addition, the model does not provide a way to integrate other factors in predicting adoption. Therefore, future studies should extend the TAM model by adding other important factors toward actual use such as institution-related factors (e.g. commission type) or userspecific constructs (e.g. innovativeness and expressiveness) to increase the model's predictive power in the e-procurement context.

\section{REFERENCES}

[1] Aboelmaged, M.G. (2010), redicting Eprocurement adoption in a developing country: an empirical integration of technology acceptance model and theory of planned behaviour, Industrial Management and Data Systems, 110(3), 392-414.

[2] Ajzen, I., \&Fishbein, M. (1980). Understanding attitudes and predicting social behavior.Englewood Cliffs, NJ: Prentice-Hall

[3] Angeles, R., \&Nath, R. (2007). Business-to-business eprocurement: success factors and challenges to implementation. Supply Chain Management: $A n$ International Journal, 12(2), 104-115.

[4] Beauvallet, G., Boughzala, Y., \& Assar, S. (2011). Eprocurement, from project to practice: Empirical evidence from the French public sector. 
[5] Croom, S. (2000)."The Impact of Web-Based Procurement on the Management of Operating Resources Supply." The Journal of Supply Chain Management, 36 (1): 4-13.

[6] Cronbach, L. J. (1951). Coefficient alpha and the internal structure of tests.Psychometrika, 16(3), 297-334.

[7] Davis, F. D. (1989). Perceived usefulness, perceived ease of use, and user acceptance of information technology. MIS Quarterly, 13(3), 319-339.

[8] Davis, F. D., Bagozzi, R. P., \& Warshaw, P. R. (1989). User acceptance of computer technology: a comparison of two theoretical models. Management science, 35(8), 982-1003.

[9] Hamner, M. (2009). Expanding the technology acceptance model to examine personal computing technology utilization in government agencies in developing countries. Government information quarterly, 26(1), 128-136.

[10] Khanapuri, V. B., \&Nayak, S. S. P., Sharma, S. Soni, M. (2011) Framework to Overcome Challenges of Adoption of E-procurement in Indian Context.In International Conference on Technology and Business Management (Vol. 208, pp. 28-30).

[11] Legris, P., Ingham, J., \& Collerette, P. (2003). Why do people use information technology? A critical review of the technology acceptance model. Information \& Management, 40, 191-204.

[12] Legris, P., Ingham, J., \& Collerette, P. (2003). Why do people use information technology? A critical review of the technology acceptance model. Information \& management, 40(3), 191-204.

[13] Liu, I-F.et al. (2010). Extending the TAM model to explore the factors that affect Intention to Use an Online Learning Community. Computers \& Education, 54 (2), 600-610,
[14] Mlinga, R. (2009). Promoting integrity in public procurement. Tanzania Procurement Journal, (2), 5, 1339.

[15] Mugenda O.M, Mugenda A.G (2003). Research Methods: Quantitative and Qualitative Approaches. Afr. Centre Technol. Studies (ACTS) Nairobi, Kenya.

[16] Park, S. Y. (2009). An Analysis of the Technology Acceptance Model in Understanding University Students' Behavioral Intention to Use e-Learning. Educational Technology \& Society, 12 (3), 150-162

[17] Pearcy, D. H., Parker, D. B., \& Giunipero, L. C. (2008). Using electronic procurement to facilitate supply chain integration: an exploratory study of US-based firms. American Journal of Business, 23(1), 23-36.

[18] PPOA (2007). Assessment of the procurement system in Kenya. Nairobi

[19] Rai, A., Brown, P., \& Tang, X. (2009). Commissional assimilation of electronic procurement innovations. Journal of Management Information Systems, 26(1), 257-296.

[20] Schoenherr, T., \&Tummala, V. R. (2007). Electronic procurement: a structured literature review and directions for future research. International Journal of Procurement Management, 1(1-2), 8-37.

[21] Teo, T. (2010).An empirical study to validate the Technology Acceptance Model (TAM) in explaining the intention to use technology among educational users. International Journal of Information and Communication Technology Education, 6(4), 1-12

[22] Venkatesh, V., Morris, M. G., Davis, G. B., \& Davis, F. D. (2003). User Acceptance of Information Technology: Towards a Unified View. MIS Quarterly, 27(3), 425-478. 